\title{
Long Term Effect of VATS Sympathectomy for the Management of Primary Hyperhidrosis, Our Experience at King Hussein Medical Center
}

Ala Mohammad Qayet, MD. JBTS ${ }^{1,3^{*}}$, Mutaz Fawaz Haddadin, MD. JBTS ${ }^{1}$, Qasim Mohammad Al-Qaisi, MD. JBTS ${ }^{1}$, Rami Ahmad Al-Qatameen, MD. JBGS ${ }^{1}$, Amany Abdullah Al-Mashagebah, RN ${ }^{2}$, Hani Abdelraheem Al-Hadidi ${ }^{1}$, Jamal Elayan Al-Ayidi ${ }^{1}$

${ }^{1}$ Thoracic Surgeon at King Hussein Medical Center, Amman, Jordan

${ }^{2}$ Thoracic surgery Coordinator nurse, King Hussein Medical Center, Amman, Jordan

${ }^{3}$ Thoracic Surgeon at King Hussein Medical Center, King Abdullah II street, PO Box 855075, Amman 11855, Jordan

DOI: $10.36347 /$ sjams.2020.v08i10.035

| Received: 15.10 .2020 | Accepted: 23.10.2020 | Published: 29.10.2020

*Corresponding author: Ala Qayet

Abstract

Original Research Article

Background: Video assisted thoracoscopic (VATS) sympathectomy is the golden standard surgical procedure for primary hyperhidrosis $(\mathrm{HH})$ nowadays. As any procedure there are immediate and long term effect of the procedure. Objective: in this study we want to review our patients and explore the short and long term effect of VATS sympathectomy. Methods: we want to review patients file and data whom had underwent VATS sympathectomy from 2017 till 2019 and their follow ups for one year. We want to investigate both immediate and long term effect and complications regarding pain, recurrence, and compensatory hyperhidrosis. Results: 210 patients was enrolled in the study. 113 males $(53.8 \%)$ and 97 females (46.1\%). Mean age was 22 years with age range from 14 to 32 years. All patient $(100 \%)$ had resolution of their symptoms post operation. 10 patients $(4.7 \%)$ had compensatory $\mathrm{HH}$ and only one patient $(0.4 \%)$ had severe compensatory $\mathrm{HH}$. No long term complication was recorded. No mortalities. Conclusion: T3-T4 VATS sympathectomy is a safe and effective method of controlling HH and has an acceptable rate of compensatory $\mathrm{HH}$.

Key words: Hyperhidrosis, pain, compensatory hyperhidrosis, VATS, sympathectomy.

Copyright $\odot 2020$ The Author(s): This is an open-access article distributed under the terms of the Creative Commons Attribution 4.0 International License (CC BY-NC 4.0) which permits unrestricted use, distribution, and reproduction in any medium for non-commercial use provided the original author and source are credited.

\section{INTRODUCTION}

Primary hyperhidrosis $(\mathrm{PHH})$ is a long standing condition that affects large number of the population. It's due to excessive production of sweats on the facial, palmer, axilla and feet area with no pathological cause (secondary to other medical condition). Although excessive sweating by itself is not a big problem but it leaves the patients with huge social and behavioral burden; making their interaction with others hard and unbearable. It also may affect their working jobs especially in handy labor [1].

Many methods of controlling $\mathrm{PHH}$ are introduced with time. Surgery by doing sympathectomy is still the only long term and most satisfying management for most of the patients [2], open mini thoracotomy was initially used for the procedure but had changed to video assisted surgery (VATS) as the introduction of minimally invasive surgery emerges; which will give same results but with minimal incisions and complications for the patients [3] which is now the gold standard surgery for PHH.

\section{MeTHODS}

Our study is a retrospective study that was held in King Hussein Medical Center, Amman, Jordan. In the thoracic surgery division. All patients' data were collected from the computerized data system of the division and the hospital patient's files.

210 patients had undergone VATS sympathectomy between Jan 2017 and Dec 2019. All patients had initial workup to rule out secondary causes; primarily by going through thorough history and physical examination, followed by normal thyroid function test. All patients were consulted about other nonsurgical modalities of treatment.

Bilateral two five millimeter ports VATS was done for all the patients in the same session, right side first in the lateral position followed by the left side. 
Sympathetic chain ablation was done for all from T2 to T4. Another pleural ablation was done across each rib (2, 3 and $4^{\text {th }}$ rib) for about 3 centimeters to make sure there is no accessory nerve presence. No chest tube was inserted and evacuation of the air was done on the table for each side intraoperatively. The dryness of hand and axilla was inspected after surgery in the recovery room.

All patients were kept for one day for initial pain management with opioids and discharged home the next day on simple analgesia.

Follow up was done initially 2 weeks post discharge, then at 12 week and another follow up visit was done by the $12^{\text {th }}$ month.

\section{RESUltS}

210 patients were involved in this study. 113 males $(53.8 \%)$ and 97 females $(46.1 \%)$. Mean age was 22 years with age range from 14 to 32 years. 185 of the patients $(88 \%)$ had both palmar and axillary $\mathrm{PHH}$, whereas 20 patients $(9.5 \%)$ had isolated palmar and only $5(2.3 \%)$ had facial. 63 patients $(30 \%)$ had previously tried other modality of treatment with no satisfying results.

All patients $(100 \%)$ had resolution of their symptoms in the first post op visit for both palmar and axillary $\mathrm{HH}$. The patients of facial $\mathrm{HH}$ had also complete resolution of their symptoms (sweating and redness). All pain was resolved with no pain related complain also. 73 patients $(35 \%)$ had also resolution of the sole $\mathrm{HH}$ to different degrees.

On the second visit still all patients had resolution of sweating in areas of previous sweating. 10 patients $(4.7 \%)$ had compensatory $\mathrm{HH}$ involving the anterior chest and back, of theses only one patient $(0.4 \%)$ had severe compensatory $\mathrm{HH}$ and had to go through life modification to accommodate with the situation, still was happy enough to have dry palms. No pain related complains was recorded.

$100 \%$ of patients at the one year follow up visit still have resolution of both palmar and axillary $\mathrm{HH}$. No pain at this stage or any disabilities were detected. The ten patients who had compensatory $\mathrm{HH}$ are still having it to variable degrees with no life threatening complications or drawbacks. 30 patients $(14 \%)$ now are having sere dryness of their palms and are using different methods of moisturizing agent with satisfactory results.

There was no immediate surgery related complications in all patients. All patients were discharged at first day post op. No mortalities were recorded.

\section{DISCUSSION}

Different approaches are described for sympathectomy in the management of primary $\mathrm{HH}$. All of which include the disruption of the sympathetic chain continuity and prevent the signal from reaching the distal receptors in palms and axilla. Clipping of the chain is one of the methods where the surgeon thoracoscopically identifies the sympathetic chain and expose it along the needed levels (T2, T3, and T4) followed by applying clips to chain [4]. Some benefits that there is no permanent anatomic disruption is made, so it can be reversed if needed epically in facial $\mathrm{HH}$ if the ganglion is affected by removing the clips early still slipping and late recurrence can be troublesome in some patients [5].

Complete VATS excision of the sympathetic chain is also advocated. Using new harmonic scalpel the surgeon identifies the chain and the excise it completely from $\mathrm{T} 2$ to $\mathrm{T} 4$ in one whole peace leaving a large defect in the chain and making sure that the conducting chain is removed permanently [6]. Others would use the harmonic scalpel to make about $5 \mathrm{~mm}$ gab at the root of the chain at the rib origin [3]. All of which giving same results as cauterizing the chain but with different operating time and cost.

Multiple studies over the time was done to denote the levels that needed to be denervation. Most of the studies agreed on the need to do T2 and T3 for proper palmar $\mathrm{HH}$ management and $\mathrm{T} 4$ is prompted for better axillary results $[7,8]$. T5 on the other hand is a controversy. In our series we only did T2, T3 and T4 with excellent results and some extra on the soles of almost one third of the patients.

Long term follow up for 6 months should good results with permanent resolution of $\mathrm{HH}$ and negligible side effects on the long term, aside from over dryness of palms in some of the patients which was dealt with effectively by variable simple hand moisturizing agents.

Compensatory $\mathrm{HH}$ is still the most annoying side effect of sympathectomy. Many series has described variable numbers of occurrence still no definite predictors or solutions for this problem [9], some series pointed that compensatory $\mathrm{HH}$ can be related to extent of denervation especially $\mathrm{T} 5$ and to severity of $\mathrm{HH}$ prior to surgery, still no solid ground was found[10].

From our humble series of patients we concluded that sympathectomy of T2, T3 and T4 is a good option for patients with excellent results and acceptable rate of compensatory $\mathrm{HH}$. 


\section{REFERENCES}

1. Banerjee AK, Edmonson R, Rennie JA. Endoscopic transthoracic electrocautery of the sympathetic chain for palmar and axillary hyperhidrosis. Br J Surg. 1990;77:1435.

2. Fernando Vannucci1, José Augusto Araújo. Thoracic sympathectomy for hyperhidrosis: from surgical indications to clinical results. J Thorac Dis. 2017;9(Suppl 3):S178-S192.

3. Dumont P, Hamm A, Skrobala D, Robin P, Toumieux B. Bilateral thoracoscopy for sympathectomy in the treatment of hyperhidrosis. Eur J Cardiothorac Surg. 1997;11:774-775.

4. Hiroshi Sugimura, Ernest Spratt, Christopher Compeau. Thoracoscopic sympathetic clipping for hyperhidrosis: Long-term results and reversibility. The Journal of Thoracic and Cardiovascular Surgery. 2009;11(6):1370-1378.

5. Juan J. Fibla Alfara, Laureano Molins Lo' pezRodo', Jorge Herna' ndez Ferra' ndez, A'ngela Guirao Montes.Effectiveness of Bilateral Clipping of the Thoracic Sympathetic Chain for the Treatment of Severe Palmar and/or Axillary
Hyperhidrosis and Facial Flushing. CIR ESP. 2019:97(4):196-202198.

6. F. Herbst, E. G. Plas, R. Fugger, A. Fritsch. Endoscopic Thoracic Sympathectomy for Primary Hyperhidrosis of the Upper Limbs. Ann. Surg. 1994;220(1):86-90.

7. Liu Y, Yang J, Liu J, et al. Surgical treatment of primary palmar hyperhidrosis: a prospective randomized study comparing $\mathrm{T} 3$ and $\mathrm{T} 4$ sympathicotomy. Eur J Cardiothorac Surg. 2009;35:398-402.

8. Kim do H, Hong YJ, Hwang JJ, Kim KD, Lee DY. Topographical considerations under video-scope guidance in the T3,4 levels sympathetic surgery. Eur J Cardiothorac Surg. 2008; 33:786-789.

9. Wait SD, Killory BD, Lekovic GP, Ponce FA, Kenny KJ, Dickman CA. Thoracoscopic sympathectomy for hyperhidrosis: analysis of 642 procedures with special attention to Horner's syndrome and compensatory hyperhidrosis. Neurosurgery. 2010;67:652-656.

10. Licht PB, Pilegaard HK. Severity of compensatory sweating after thoracoscopic sympathectomy. Ann Thorac Surg. 2004;78:427-431. 